\title{
Las Empresas Asociadas y el Efecto Fiscal en las Utilidades de Empresas de Exportacion: Caso de Sonora, México
}

\section{Associated companies and the tax effect on the profits of export companies: Sonora case, Mexico}

\author{
Amado Olivares \\ Josefina Ochoa \\ José María Guereña \\ UNIVERSIDAD DE SONORA, MÉXICO \\ HTTPS://DOI.ORG/10.22370/RPE.2020.9.2445
}

\section{RESUMEN}

Se pretende realizar esta investigación con la finalidad de analizar y evaluar la actividad de las empresas exportadoras de Sonora, México con empresas asociadas e independientes las implicaciones fiscales en las utilidades, en los precios de transferencia y el marco legal de la Ley del Impuesto Sobre la Renta (LISR) establecida en la Secretaria de Hacienda y Crédito Público en México, para asegurar la imposición de impuestos apropiada y evita los problemas de doble tributación con otros países, y minimizar los problemas entre los fiscos de los países, además de buscar ser promotor de los acuerdos internacionales y la inversión.

La investigación es de tipo descriptiva y de diseño transversal, realizada durante el 2015, se aplicó estadística paramétrica con el paquete SPSS, versión 21 y se utilizó el directorio de PROMEXICO o Banco Nacional de Comercio Exterior y se aplicó un muestreo aleatorio simple se determinó una muestra de 30 empresas, y se encontró que todas las empresas aplican el método de precios sombra o transferencia, y así se evita la distorsión en el pago de impuestos y la transferencia de utilidades a otros países. El $60 \%$ de las empresas analizadas realizan operaciones con empresas asociadas y un $40 \%$ con empresas independientes. Las variables precios sombra o de transferencia, importación de materia prima y pago por regalías y dividendos explican en un $79 \%$, $67.2 \%$, y $56.7 \%$ respectivamente, la determinación de los ingresos netos, mientras que el pago de intereses, y el uso de marca solo en un $27 \%$ y $11.4 \%$.

Palabras claves: empresas asociadas, aranceles, obligaciones fiscales.

\section{SuMmary}

This research is intended to be carried out in order to analyze and evaluate the activity of exporting companies from Sonora, Mexico with associated and independent companies, the tax implications on profits, transfer prices and the legal framework of 
the Tax Law. Income (LISR) established in the Ministry of Finance and Public Credit in Mexico, to ensure the appropriate imposition of taxes and avoid double taxation problems with other countries, and minimize problems between the treasuries of the countries, in addition to seeking to be a promoter of international agreements and investment.

The research is descriptive and of cross-sectional design, carried out during 2015, parametric statistics were applied with the SPSS package, version 21 and the directory of PROMEXICO or National Bank of Foreign Trade was used and a simple random sampling was applied, a sample of 30 companies, and it was found that all companies apply the shadow or transfer pricing method, thus avoiding distortion in the payment of taxes and the transfer of profits to other countries. $60 \%$ of the companies analyzed carry out operations with associated companies and $40 \%$ with independent companies. The variables shadow or transfer prices, import of raw materials and payment of royalties and dividends explain in $79 \%, 67.2 \%$, and $56.7 \%$ respectively, the determination of net income, while the payment of interest, and the use of marks only $27 \%$ and $11.4 \%$. Keywords: associated companies, tariffs, tax obligations. 


\section{IntroducCión.}

\section{Antecedentes}

Una empresa es una entidad socioeconómica que agrupa a los autores de la producción: tierra, trabajo y capital, coordinados y optimizados por una administración; con el objeto de producir un bien, prestar un servicio o explotar un recurso que satisfaga una necesidad a cambio de un beneficio. En ese sentido, las operaciones realizadas, tanto por personas físicas como morales, en sus actividades empresariales o de servicios, conforman una empresa.

En función de su plan de negocios y del éxito logrado, las empresas tienden a crecer y expandirse dentro de la propia demarcación territorial del país donde residen o, inclusive, fuera de ella; es decir, dada su política de globalización, evalúan la posibilidad de crear establecimientos permanentes dentro o fuera del estado al que pertenecen, y/o de constituir nuevas compañías en los términos que dispongan las leyes reglamentarias de los países sede.

Así, las personas físicas y morales se desempeñan a través de sucursales, agencias, oficinas, fábricas, talleres u otros lugares en los que sea factible la realización de negocios, los cuales, para efectos de las leyes domésticas y de los convenios internacionales para evitar la doble tributación, son considerados como empresas permanentes.

También realizan su objeto social mediante compañías subsidiarias o asociadas, en razón de la participación en el capital social de estas por parte de la tenedora: más de $50 \%$ de las acciones con derecho a voto. Es de aclarar que dos o mas de la compañías subsidiarias o asociadas adquieren la categoría de afiliadas cuando, de forma significativa, poseen accionistas o administración común.

Al decidir la ubicación, constitución o compra de unidades de negocio en el extranjero, las empresas constituyen grupos multinacionales, tornándose en partes relacionadas entre sí, por lo que al operar entre ellas, las administraciones tributarias de los estados involucrados pueden encontrarse ante la recaudación de la Ley del Impuesto Sobre la Renta (LISR), cuya base no les resulta necesariamente confiable.

En Sonora México de las actividades económicas las empresas que 
más apoyan al desarrollo de Sonora son las empresas exportadoras y también son muchas las complicaciones en relación con las actividades de exportación que se deben de realizar, entre ellos destacan los controles en sus precios, es por eso que nace el interés de realizar esta investigación y enfocarlo a este estado.

\section{Definición del Problema.}

Existe un desconocimiento en las empresas de exportación sobre el marco legal que establece la Ley del Impuesto sobre la Renta en el capítulo de los precios sombra o de transferencia, para el registro de los precios y utilidades, aun cuando es de mucha utilidad para la toma de decisiones en las empresas y mas aun si se tiene la obligación de hacerlo, para hacer la detección y evitar la doble tributación, esto genera además infracciones y multas que encarecen mas en la empresa los costos administrativos.

Este tema tributario es de mucha importancia en México, ya que repercute en las arcas del erario federal y esto es debido a las prácticas que estas empresas realizan y cuya tendencia es desviar sus utilidades trasladándolas a territorios con tasas impositivas menores o, a territorios llamados "paraísos fiscales".

\section{JUSTIFICACIÓN.}

El comportamiento en el ámbito fiscal de las empresas exportadoras con sus empresas asociadas o relacionadas ha sido regulado por los Estados a través de la determinación de los precios de transferencia. En el caso del marco jurídico en México se han establecido normas fiscales y financieras durante los últimos años, principalmente después de la incorporación de México a la Organización para la Cooperación y Desarrollo Económico (OCDE). Los lineamientos de la OCDE han incidido en la legislación mexicana, particularmente la Ley del Impuesto sobre la Renta, e estableciendo un tratamiento especial del régimen fiscal y precios de transferencia.

Es importante realizar esta investigación ya que es muy poco conocido en el medio empresarial, aun cuando se tenga la obligación de manejarlo y creo que esta investigación ayudaría mucho a los 
exportadores mexicanos y aquellos que se interesen en el tema y todavía mejor que los alumnos que en la actualidad egresan de las licenciaturas y de posgrado, puedan utilizar esta investigación para poder proporcionar un mejor servicio a la comunidad y a la correcta aplicación de las obligaciones que estogenera.

\section{MARCO TÉORICO:}

LOS PRECIOS DE TRANSFERENCIA EN MÉXICO.

El comercio en el mundo, "sesenta y cinco por ciento", se lleva a cabo con grupos de empresas que están vinculadas en partes relacionadas. En México cuando una empresa:

Participa de manera directa o indirecta en la administración, control o capital de otra, o cuando una persona o grupo de personas participe, directa o indirectamente, en la administración, control o en el capital de dichas personas, o cuando exista vinculación entre ellas de acuerdo con la legislación aduanera (Baker \& McKenzie, 2004, p. 1).

En México los contribuyentes están obligados a llevar contabilidad (LISR 2009 artículo 86 fracción I), la misma, estará integrada por la documentación comprobatoria que soporte las aplicaciones contables y determinación de los precios de transferencia. También están obligados a presentar junto con la declaración anual de impuestos, "la información de las operaciones que realicen con partes relacionadas residentes en el extranjero, efectuadas durante el año de calendario inmediato anterior."

Se considera parte relacionada, así como sus establecimientos permanentes, la casa matriz y sus establecimientos permanentes. Si una parte no relacionada celebró contrato "joint venture" (conocido como asociación en participación) con alguna empresa, se considera en México, parte relacionada para efectos de precios de transferencia. (Raby, 2008, p. 507)

En México cuando una empresa participa de manera directa o indirecta en la administración, control o capital de otra, o cuando una persona o grupo de personas participe, directa o indirectamente, en la administración, o control o en el capital de dichas personas, o 
cuando exista una vinculación entre ellas de acuerdo con la legislación aduanera (Backer \& McKenzie, 2004, p.1).

Concepto de Precios de Transferencia de acuerdo al Instituto Mexicano de Contadores Públicos, (IMCP, 1992-1997):

- En el boletín C-13 de las Normas de Información Financiera (NIF), del IMCP pretende aclarar el término, pero tampoco presenta una definición directa, ya que se aboca a aclarar quiénes son partes relacionadas de una sociedad determinada a la que identifica como informante.

Existe una característica importante que hace la diferencia en los precios de transferencia, pues deben ser fijados o convenidos entre compañías multinacionales o no:

-El término precio de transferencia denota el precio pactado entre dos o más divisiones que pertenecen a un mismo grupo de empresas, sea éste multinacional o no. (Cruz Camacho, 2001:2).

- Camacho C. J. (2001) y el Instituto de Ejecutivos de Finanzas Internacionales (IMEFI 2001), definen a los precios de transferencia como: La cantidad pagada o cobrada en transacciones celebradas entre sujetos pasivos relacionados, ya sea en forma accionaria o económica.

La Organización para la Cooperación y el Desarrollo Económico (OCDE, 2004) da a conocer el significado de los valores en cuestión en el siguiente sentido: Los precios de transferencia son los precios a los que una empresa transmite bienes materiales y activos intangibles o presta servicios a empresas asociadas.

La OECD (2009), es un organismo internacional cuyos objetivos fundamentales son el intercambio de información, la armonización de la política entre sus países miembros en un gran número de áreas, la promoción del bienestar económico y social de los ciudadanos de los países miembros de la misma, todo ello, basado en la buena marcha de la economía mundial y con relación a los precios de transferencia, los países miembros de la OECD buscan eliminar los efecto de condiciones especiales que afectan los niveles de ganancia.

El principio de precio libre de mercado tiene un doble objetivo, y siguiendo los lineamientos de Mendoza H y Ahrens M. (2005), es un mecanismo que asegura la imposición de impuestos apropiada y 
evita los problemas de doble tributación al minimizar los problemas entre los fiscos de los países, además de buscar ser promotor de los acuerdos internacionales y la inversión. La solución a ello radica en aplicar apropiados precios de transferencia. Los precios de transferencia son aquellos con los que una empresa ofrece mercancías, servicios e intangibles a una empresa relacionada. La determinación adecuada de ello es muy importante, porque involucra que los ajustes determinados para una autoridad fiscal del país de una jurisdicción impliquen el hacer el ajuste correspondiente en la parte de ganancias de la otra parte afectada en el otro país, ello a fin de minimizar el riesgo de la doble imposición. Ahora bien, al hacer un análisis de las acepciones anteriores y considerando de todas ellas los aspectos más importantes, es posible integrar la siguientedefinición:

"Precios de transferencia son los valores convenidos entre partes relacionadas durante la celebración de operaciones internacionales, comerciales o de servicios, dispuestos a la observación de ciertos lineamientos orientados a demostrar a la autoridad que la sola relación de las partes no ha incluido el resultado de sus negociaciones y, por consiguiente, no ha originado un efecto fiscalmente favorable a sus intereses corporativos".

De acuerdo a la ley del Impuesto sobre la Renta (2004 - 2014), la figura en los precios de transferencia trata de impedir que las utilidades o pérdidas generadas en un país sean trasladados a otro, por medio de operaciones artificiales, tales como intereses, dividendos, regalías, etc., formas a través de las cuales los contribuyentes buscan minimizar la carga tributaria remitiendo utilidades de un país hacia otro. Lo que se busca con esta figura es evitar la manipulación de las operaciones que a través de tasas reducidas distorsionen la política fiscal de los países que intervienen, García C. y Cabrera N. A. (2005).

Por todo lo anterior y siguiendo los lineamientos de los Métodos en materia de Precios de Transferencia de Rizo R. M. y Guerrero C. A. (2006), podemos concluir que a través de los precios de transferencia lo que se pretende es que en las operaciones de grupos empresariales se apliquen reglas de grabación bajo el principio de precio de libre mercado, de manera que se apliquen entre partes relacionadas las 
mismas condiciones que en operaciones independientes.

\section{MÉTOdos PARA DETERMINAR LOS PRECIOS DE TRANSFERENCIA}

Los métodos que se puede aplicar en materia de precios transferencia, de acuerdo a Rizo R. M. y Guerrero C. A. (2006), a continuación se presentan:

A. Método de PRecio Comparable no CONTROLAdo o PRECio DE MERCADo (Рм), que consiste en considerar el precio o el monto de las contraprestaciones que se hubieran pactado con o entre partes independientes en operaciones comparables. Este método lleva a la necesidad de hacer una comparación de operaciones idénticas o similares y el primer problema es determinar si existen operaciones comparables sólo, algunas de las razones por las que no es posible obtener precios comparables sólo siguientes:

Porque no existe mercado para esos productos, porque no se surten a empresas independientes, porque se trata de productos semiterminados que no son comparables con otros existentes en el mercado, porque el cliente independiente es tan pequeño que no puede lograr los descuentos normales, porque se trata de actividades únicas y singulares, porque las condiciones económicas de un país sean diferentes a las de otro. Este método usa principalmente para estudios de precios de transferencia vinculados con "las tasas de interés, los honorarios, las rentas, o montos para otorgar el uso, goce o enajenación de bienes tangibles, así como cuando se cobren regalías por la explotación o transmisión de un bien intangible" (Bettinger, 2008, p. 79).

Además, este método es el que representa el valor real, el de mercado, pues busca equiparar las operaciones entre partes relacionadas con las que sean celebradas en condiciones iguales o similares entre partes independientes en condiciones de mercado que no pueda manipular el valor de las operaciones. La LISR sólo obliga a los contribuyentes que celebren operaciones con partes asociadas residentes en el extranjero. El objetivo de los precios de transferencia es, evitar la manipulación de las operaciones que a través de tasas 
impositivas reducidas distorsionen la política fiscal de los países que intervienen. Veamos el siguiente caso:

Tabla no. 1 Precios comparables no controlados* (PM): Caso No. I

\begin{tabular}{|c|c|c|}
\hline $\begin{array}{c}\text { Empresa } \\
\text { Mexicana REAL }\end{array}$ & $\begin{array}{c}\text { Empresa Independiente, } \\
\text { en el extranjero }\end{array}$ & $\begin{array}{c}\text { Empresa Asociada, en el } \\
\text { Extranjero }\end{array}$ \\
\hline Ingresos (Pm) & Ingresos & \\
\hline -Costos & -Costos & \\
\hline $50+$ & Ut. $\quad 60=110$ & \\
\hline Tasa Impto: $28 \%$ & Tasa Impto: $\mathbf{4 0 \%} \mathbf{2 4}=\mathbf{3 8}$ & \\
\hline MANIPULADA & & MANIPULADA \\
\hline Ingresos $(\mathrm{Pm}) \quad \mathbf{\$ 2 0 0}$ & & Ingresos $\$ 210$ \\
\hline -Costos & & -Costos \\
\hline $100+$ & & $10=110$ \\
\hline \begin{tabular}{|l|l|}
$\begin{array}{l}\text { Tasa Impto: } 28 \% \\
+\end{array}$ & $\mathbf{2 8}$ \\
\end{tabular} & & Tasa Impto: $40 \% \mathbf{1 4}=\mathbf{3 2}$ \\
\hline Pago regalías, divid. 1.5 & & Pago reg. divid. .15 \\
\hline $\begin{array}{ll}\text { Ut. Total. } & 98.5 \\
+\end{array}$ & + & Ut. Total. $\quad 9.85=108.35$ \\
\hline Tasa Impto: $28 \% \mathbf{2 7 . 5 8}$ & + & $\begin{array}{l}\text { Tasa Impto: } 40 \% \mathbf{3 . 9 4}= \\
\text { n31.5 }\end{array}$ \\
\hline
\end{tabular}

Fuente: Ley del Impuesto sobre la Renta, SHCP (2014). * Millones de pesos

Al analizar los datos de la tabla No. 1 se puede observar cómo se puede distorsionar el pago de impuestos de $\$ 38$ millones pesos al comercializar con una empresa independiente, y de

$\$ 32$ millones de pesos al comercializar con una empresa asociada, y una transferencia de utilidades hacia el país extranjero. Y si además la empresa mexicana y asociada paga regalías y dividendos la utilidad total disminuye de $\$ 110$ a 98.35 millones de pesos, y por ende pagarían menos impuestos de $\$ 32$ a 31.5 millones de pesos. 
B. Método de precio de Reventa, que consiste en determinar el precio de adquisición de un bien, de la prestación de un servicio o de la contraprestación de cualquier otra operación entre partes relacionadas, multiplicando el precio de reventa, o de la prestación del servicio o de la operación de que se trate por el resultado de disminuir de la unidad, el por ciento de utilidad bruta que hubiera sido pactado con o entre partes independientes en operaciones comparables. Para los efectos de esta fracción, el por ciento de utilidad bruta se calculará dividiendo la utilidad bruta entre las ventas netas.

De una manera más sencilla, este párrafo se refiere a que es necesario determinar elprecio de adquisición y se obtiene considerando el Precio de reventa con partes independientes, multiplicado por la unidad (1) menos el por ciento de utilidad bruta con partes independientes. Dicho por ciento, será igual a dividir la Utilidad Bruta entre las Ventas Netas.

Ejemplo: Una empresa vende computadoras en $\$ 10,000$ y tiene un $\%$ de utilidad bruta del $34 \%$, y considera que su costo en operaciones con partes relacionadas de $\$ 8,000$, llevará a la autoridad a determinar que el precio deficiente bien y sólo de $\$ 6,600$.

$\$ 10,000(1-0.34)=\$ 10,000(0.66)=\$ 6,600$. Aplicando los datos del caso 1 quedaría:

$150(1-.33)=150-49.5=100.5$ por lo que se recomienda países con menor tasas de impuestos.

C. Método de costo adicionado, que consiste en determinar el precio de venta de un bien, de la prestación de un servicio o de la contraprestación de cualquier otra operación, entre partes relacionadas, multiplicando el costo del bien, del servicio o de la operación de que se trate por el resultado de sumar a la unidad el por ciento de utilidad bruta que hubiera sido pactada con o entre partes independientes en operaciones comparables. Para los efectos de esta fracción, el por ciento de utilidad bruta se calculará dividiendo la utilidad bruta entre el costo de ventas. Este método consiste en determinar el precio de venta de un bien denominado, tomando como base el costo de los bienes, multiplicado por el resultado de las unidad (1) más el por 
ciento de la utilidad bruta, este por ciento se obtiene de la división de la utilidad bruta entre el costo de venta, también denominado como margen de utilidad.

Ejemplo: Un contribuyente vende a su parte relacionada con televisor en $\$ 2,800$ que le costó $\$ 2,000$ y a partes independientes no vende entre $\$ 3,000$. Ello implica que la autoridad estime que debió vender a $\$ 3,000$ a su parte relacionada.

$\%$ de utilidad bruta $=\$ 1,000 / \$ 2,000=50 \% \quad \$ 2,000(1+50 \%)$ $=\$ 2,000(1.50)=\$ 3,000$. Si aplicamos los datos del caso 1 quedaría: $100(1+.50)=100+50=150$ por lo que se recomienda países con menor tasas de impuestos.

\section{Objetivos e hipotesis. Objetivo general:}

Esta investigación se realiza con la finalidad de analizar y evaluar todo lo relacionado con los precios de transferencia, pagos de importación de materia prima, pago de marca e intereses, desarrollo de proyectos y sus implicaciones fiscales en las empresas que se dediquen a la exportación de sus productos a empresas asociadas e independientes, para poder contribuir al conocimiento sobre la determinación de las utilidades netas y los requerimientos fiscales que exigen los fiscos de los países con los que comercializamos, y asegurar la imposición de impuestos apropiada y evita los problemas de doble tributación.

\section{Objetivos específicos:}

1. Hacer la detección de las empresas que realizan exportaciones con empresas asociadas y cuales con independientes, e identificar el sector económico al quepertenecen.

2. Describir los métodos de precios sobra o transferencia que establece la LISR.

3. Las Utilidades Netas en las actividades de exportación, se ven afectada por los precios sombra o de transferencia, la importación de materia prima, pago de intereses, pago por uso de marca, de desarrollo de proyectos y según sea el país con el que comercialice.

4. Identificar que empresas exportadoras, usan en sus registros los precios sombra o transferencias para obtener mayores utilidades. 


\section{Hipótesis:}

H1. Las empresas exportadoras de Sonora, si cumplen con las obligaciones fiscales vigentes que establecen las LISR, en relación a los precios de transparencia.

H2. Las variables de Precios Sombra o Transferencia, de Importación de Materia Prima, y el Pago de regalías y dividendos, guardan una relación directa con la determinación de los Ingresos Netos.

H3. Las variables Pago de intereses y Pago por uso de marca de producto guardan una relación directa en los Ingresos Netos.

\section{Metodología.}

La metodología plantea una investigación tipo descriptiva y de diseño transversal, ya que se desarrolló durante el 2015, con un enfoque mixto, mayormente cuantitativa. Se inicia con el análisis de la Ley del Impuesto Sobre la Renta, El Código Fiscal de la Federación, de Tratado de Libre Comercio para hacer la detección y evitar la doble tributación con los países con los que comercializamos. Se utilizó el directorio de PROMEXICO o Banco Nacional de Comercio Exterior y con un muestreo aleatorio simple se determinó una muestra de 30 empresas, las cuales fueron seleccionadas con el método de la Ley de los Grandes Números del Premio Nobel en Economía John Nash (1996). Del Sector Agrícola (Hortalizas, frutales, granos), del Sector Industrial (autos, cárnicos, alimentos), y del Sector minero (Cobre, y oro), y se aplicó el paquete estadístico SPSS, versión 21. Se procesó y analizo la información y se obtuvieron las correlaciones dela información, generando la valoración integral sobre el precio de transferencia, importación de materia prima, pago de regalías y dividendos, pago de intereses y pago de uso de marca deproducto.

En el instrumento se utilizó para valorar la escala de Lickert de 1 al 5, y se aplicó el cuestionario expuesto en la Tabla No.4 y además se validó su confiablidad interna, obteniendo un Alfa de Cronbach con un valor de .89. Las fuentes de información utilizadas fueron primarias y secundarias. Las fuentes primarias fueron los cuestionarios aplicados a las empresas de exportación. 
Para realizar la investigación se examinaron las disposiciones de la Ley del Impuesto Sobre la Renta (2014), Código Fiscal de la Federación (2009-2011), las guías de precios de transferencia para empresas multinacionales y administraciones fiscales de la OECD (1995), así como libros y revistas de los diversos autores que han estudiado los métodos de valuación de los precios de transferencia en México.

La metodología utilizada se describe el procedimiento a continuación:

El valor de los niveles de Ingresos Netos $(\mathrm{IN})=\mathrm{f}(\mathrm{V} 1, \mathrm{~V} 2, \mathrm{~V} 3, \mathrm{~V} 4$ V5.). VI: Variables Independientes

V1: Precios sombra o de Transferencia V2: Importación de Materias Primas

V3: Pago por regalías y dividendos V4: Pago de intereses V5: Por uso de marca de producto. Primer paso:

Valor promedio de los Ingresos Netos $(V I)=\underline{\text { Sumatoria de cada }}$ un indicador por VI

No. Total de empresas

Segundo paso seria, la sumatoria del valor de cada una de las VI del IN, entre el número de empresas: Valor promedio de IN = Sumatoria del Valor promedio de las VI

No. Total de empresas

Como las medidas de distancia son sensibles a las diferencias, es necesaria la estandarización de datos para evitar que las variables con gran dispersión tengan un mayor efecto en la similaridad. La forma de estandarizar más común es restarle a cada observación la media de la variable y este resultado dividirlo entre su desviación estándar, Anderson, et al 2013.

\section{Resultados y discusión.}

Los resultados obtenidos en la investigación realizada en relación con las actividades que realizan las cinco principales empresas exportadoras de Sonora, México y que son en el sentido de ver si realizan operaciones en el extranjero con empresas asociadas, son las que se muestran a continuación en la Tabla No. 2. 
Tabla No. 2 Aplicación DEL PREcio DE TRANSFERENCia EN EMPRESAS ASOCIADAS E INDEPENDIENTES.

\begin{tabular}{|l|c|c|}
\hline EMPRESAS & $\begin{array}{c}\text { Aplicación del precio de transferencia } \\
\text { de la LISR. }\end{array}$ & $\begin{array}{c}\text { Escala de } \\
\text { Lickert. }\end{array}$ \\
\hline Asociadas $\mathbf{6 0} \%$ & $100 \%$ & $1-5$ \\
\hline Independiente $40 \%$ & $100 \%$ & $1-5$ \\
\hline
\end{tabular}

\begin{tabular}{|l|lc|c|}
\hline EMPRESAS & $\begin{array}{l}\text { Puntos a Evaluar con } \\
\text { Empresas Asociadas }\end{array}$ & $\begin{array}{c}\text { Escala de } \\
\text { Lickert. } \\
1-5\end{array}$ \\
\hline Sector Agrícola : & 1. Exportación de Productos. & SI & 5.00 \\
18 empresas: 60\% & 2. Importación de Materia Prima. & SI & 3.35 \\
-Hortalizas (3), & 3. Pago de Regalías y dividendos. & SI & 2.85 \\
-Frutales (3), & 4. Pago de Intereses. & NO & --- \\
- Granos (3). & 5. Pago por uso de marca. & NO & --- \\
Total 9 empresas. & & & \\
\hline Sector Industria: & 1. Exportación de Productos. & SI & 5.00 \\
- Automotriz (2), & 2. Importación de Materia Prima. & SI & 3.35 \\
- Cárnicos (2), & 3. Pago de Regalías y dividendos. & SI & 2.85 \\
- Alimentos (2). & 4. Pago de Intereses. & SI & 1.35 \\
Total 6 empresas & 5. Pago por uso de marca. & SI & .60 \\
\hline Sector Minero: & 1. Exportación de Productos. & SI & 5.00 \\
- Mina de Cobre (2) & 2. Importación de Materia Prima. & SI & 3.35 \\
-Mina Oro (1), & 3. Pago de Regalías y dividendos. & SI & 2.85 \\
Total 3 empresas. & 4. Pago de Intereses. & NO & --- \\
& 5. Pago por uso de marca & NO & --- \\
\hline
\end{tabular}

\begin{tabular}{|l|lc|c|}
\hline EMPRESAS & \multicolumn{2}{|c|}{$\begin{array}{c}\text { Puntos a Evaluar con } \\
\text { Empresas Independientes }\end{array}$} & $\begin{array}{c}\text { Escala de } \\
\text { Lickert. } \\
1-5\end{array}$ \\
\hline Sector Agrícola : & 1. Exportación de Productos. & SI & 5.00 \\
$\mathbf{1 2}$ empresas: 40\% & 2. Importación de Materia Prima. & SI & 3.35 \\
- Hortalizas (2), & 3. Pago de Regalías y dividendos. & SI & 2.85 \\
- Frutales (4), & 4.Pago de Intereses. & NO & -- \\
- Granos (2). & 5.Pago por uso demarca. & NO & -- \\
\hline
\end{tabular}




\begin{tabular}{|l|ll|c|} 
Total 8 empresas. & & & \\
\hline Sector Industria: & 1. Exportación de Productos. & SI & 5.00 \\
- Cárnicos (2), & 2. Importación de Materia Prima. & SI & 3.35 \\
- Alimentos (2). & 3. Pago de Regalías y dividendos. & SI & 2.85 \\
Total 4 empresas & 4.Pago de Intereses. & NO & --- \\
& 5. Pago por uso de marca. & NO & --- \\
\hline
\end{tabular}

Fuente: Elaboración propia a partir de la información obtenida.

Analizando la tabla 2 se encontró que el 100\% de las Empresas Exportadoras por lo menos dos tipos de operaciones con empresas extranjeras, pues todas ellas exportan su producción a los Estados Unidos de América, Perú y Argentina además importan temporalmente parte de su materia prima, principalmente el material de empaque. Solamente seis de ellas pagan intereses a empresas de los Estados Unidos de América y únicamente dos de ellas pagan por uso de marca de producto. De las operaciones internacionales que realizan cada una de las empresas analizadas, el 100\% de ellas las realizan con partes asociadas e independientes, por lo cual en ninguno de los casos se observa que haya inversión por parte de las empresas locales en el capital social de las empresas extranjeras con las que realizan operaciones internacionales, ni estas últimas tienen invertido en el capital de dichas empresas mexicanas.

Se observa en la tabla 2, que el 100\% de las empresas exportadoras de Sonora, México consideradas, utilizan los precios de transferencia que se establecen en las disposiciones Fiscales, y cumplen con la obligación dispuesto con la LISR, lo que confirma la H1. 
Figura 1: Modelo de Ingresos Netos y sus correlaciones de PeArson (R) y COEFICIENTE de Determinación $\left(\mathrm{R}^{2}\right)$.

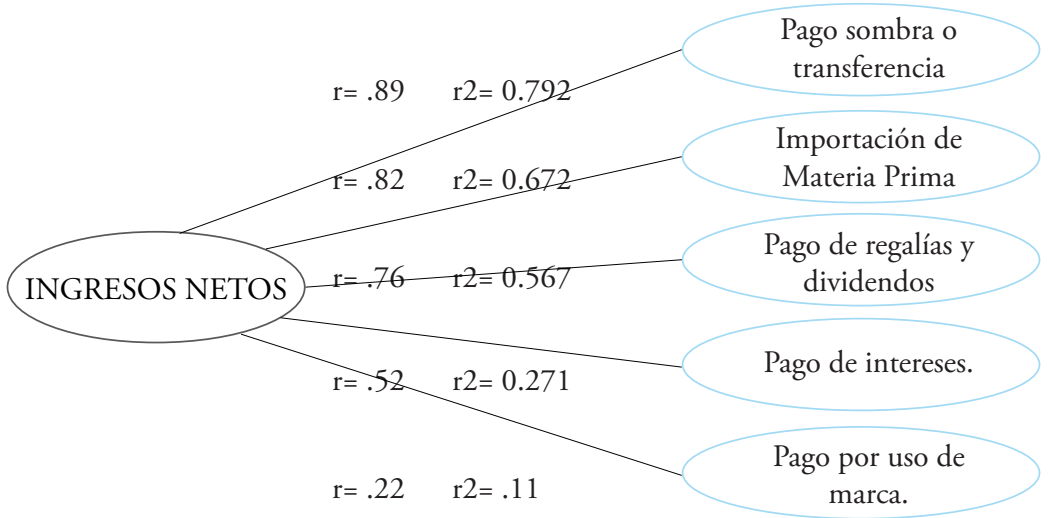

Fuente: Ley del Impuesto sobre la Renta, SHCP (2014).

Las variables de Precios de Transferencia obtuvo un ${ }^{\mathrm{r}} 2=.792$ y $\mathrm{r}=.89$; la Importación de materia Prima obtuvo un $\mathrm{r}^{2}=.672$ y r $=.82$, y el Pago de regalías y dividendos obtuvo $\mathrm{r}^{2}=.567$ y $\mathrm{r}=.76$, lo que confirma que estas categorías si explican en un nivel medio alto los niveles de Ingresos Netos, lo cual confirma la H2. Mientras que las variables de Pago de intereses obtuvo $\mathrm{r}^{2}=.27$ y $\mathrm{r}=.52$; y la variable Pago por uso de marca obtuvo un $\mathrm{r}^{2}=.114$ y $\mathrm{r}=.22$; lo que confirma que estas variables explican en un nivel muy bajo los niveles de Ingresos Netos, por lo que se rechaza la $\mathbf{H 3}$.

Aun cuando no se tenga la obligación Fiscal de llevar a cabo algún método para determinar los Precios de Transferencia en las empresas que no realizan operaciones con partes asociadas, es recomendable estar monitoreando los precios a que se realizan las operaciones por las demás empresas, para poder tomar decisiones acertadas en relación con el momento en que se debe mantener, subir o bajar el precio de venta de los productos de exportación. 


\section{Conclusiones.}

El movimiento de capitales y bienes permiten a las empresas que celebran operaciones con partes relacionadas utilizar precios en función de su interés. Cuando se fijan los Precios de Transferencia (PT) para operaciones entre partes relacionadas éstos inciden en distintas jurisdicciones, y en más de un erario fiscal federal. Si un PT se establece inapropiadamente podría afectar al estado de la empresa donde tiene su residencia fiscal o crear un beneficio directo para ella.

Cuando se usan los métodos de precios de transferencia, los beneficios pueden trascender en un incremento en la inversión de los socios, mediante una disminución de costos, gastos de operación o descuentos sobre compras, o en el aumento del ingreso. El efecto se reconoce cuando el grupo de empresas consolida su información financiera.

Si bien es cierto que la legislación propone métodos para fijar precios de transferencia, la regulación no es estricta al respecto, pues los mismos lineamientos de la OCDE, proponen la consideración ante el comportamiento real de las transacciones, abriendo la posibilidad de comparar información en una base de datos, ya sea pública o privada.

Es conveniente que los sistemas de base de datos sean íntegros ya que esto proporciona seguridad al usuario de la información. La base de datos debe ser genuina y confiable. Si ésta no proporciona calidad en su información, pueden ayudar a desvirtuar el pago de aranceles; el aprovechamiento de subsidios fiscales; disminuir el ISLR, así como los impuestos indirectos y el impuesto correspondiente a las actividades especiales; alterar el riesgos cambiarios en el desvío de capitales de países, inclusive influir en la competencia con la apertura de nuevos mercados para reducirla.

México ha entrado al mundo de la globalización y en el ámbito internacional existen muchas empresas que realizan operaciones con partes relacionadas debido a las necesidades de crecimiento y extensión por tal razón nació la inquietud de llevar a cabo este trabajo.

Como se puede apreciar en el desarrollo de este trabajo, el 
procedimiento de los precios de transferencia, permiten a las autoridades fiscales verificar que las operaciones que efectúen los contribuyentes se apeguen a la realidad económica y comercial, debiéndose cubrir los gravámenes que correspondan y no, por actos transaccionales que disminuyan estos, afectando la recaudación.

Los precios de transferencia permiten verificar que los precios de los bienes y servicios, sean los que corresponda al mercado nacional e internacional y que en caso de que estos se distorsionen, se cuente con elementos que permitan evitar, regular o sancionar un efecto nocivo en el comportamiento comercial o de servicios que tenga repercusión en el cumplimento impositivo.

Es necesario que las empresas agrícolas, manufactura y mineras realicen existan operaciones internacionales con partes relacionadas, por lo que requieren darle valor agregado a sus productos. Por tal motivo, al aplicar precios sombra o de transferencia existe obligación fiscal al respecto.

Las empresas agrícolas, manufactura y mineras se apegan a los precios de transferencia con el método de precios libres de mercado se apegan a la obligatoriedad fiscal establecida en México.

En el Sistema Fiscal Mexicano, el principio de precios de transferencia se establece en la Ley del Impuesto sobre la Renta, en donde se establece que las autoridades fiscales podrán determinar los ingresos acumulables y deducciones autorizadas de los contribuyentes, mediante la determinación del precio o monto de la contraprestación en operaciones celebradas entre partes asociadas, lo que implica a su vez y mediante procedimientos no necesariamente de naturaleza impositiva, que se obtengan conocimientos o datos que demuestren que la empresa que se sitúe en tal situación pretende obtener un beneficio indebido y que este a su vez, produce un efecto negativo de carácter fiscal.

Para estos efectos o sea, para determinar el precio de transferencia y por lo tanto la generación de un crédito fiscal producto del diferencial que se obtiene en operaciones celebradas entre personas morales, residentes en el país o en el extranjero, personas físicas y establecimientos permanentes en el país de residentes en el extranjero, 
si una de ellas posee interés en los negocios de otra, o bien existen intereses comunes entre ambas, $\mathrm{o}$ inclusive cuando una tercera persona tenga interés en los negocios o bienes de aquellas, se deberán aplicar los métodos que establece la Ley del Impuesto sobre la Renta.

Además es importante considerar que el determinar por parte de la autoridad fiscal un precio de transferencia, obliga al sujeto pasivo a corregir su resultado fiscal, que por lo regular es disminuyendo las deducciones autorizadas o aumentando los ingresos acumulables, para que resulte un impuesto a cargo de la empresa revisada.

En las empresas exportadoras del estado de Sonora, en las que se pensó que podían tener la obligación fiscal de aplicar las disposiciones en relación con los precios de transferencia, si es para ellas indispensable la aplicación de dichos principios, pues para que exista dicha obligación, es necesario que existan operaciones internacionales con partes asociadas además de exportar.

Cabe mencionar que aun cuando si existe la obligación de aplicar los precios de transferencia para efectos fiscales, es importante llevarlos a cabo para la toma de decisiones, pues ayuda en mucho que en todo momento sepan las empresas exportadoras cual es el precio al que pueden vender o dejar de hacerlo al extranjero, para que no exista al final de las operaciones una pérdida contable.

Estar monitoreando los precios a que se realizan las operaciones por las demás empresas, para poder tomar decisiones acertadas, en relación con el momento en que se debe mantener, subir o bajar el precio de venta de los productos de exportación. Algunas pueden utilizan el método 2 y 3 lo que implica buscar países con menor tasas impositivas.

\section{Vi. REFERENCIAS BIBLIOGRAFICAS.}

ACADEMIA de Estudios Fiscales de la Contaduría Pública A.C. (1992). Tratados para evitar la Doble Imposición. Primera ed. México. Instituto Mexicano de Contadores Públicos 258.

ACADEMIA de Estudios Fiscales. (1994). Entorno Fiscal de la Apertura Económica. Primera ed. México. Instituto Mexicano de Contadores Públicos A.C. 210. 
ACADEMIA de Estudios Fiscales. (1994). Implicaciones Fiscales De Las Operaciones Internacionales. Primera ed. México. Instituto Mexicano de Contadores Públicos A.C. 147.

ACADEMIA de Estudios Fiscales. (1997). Maquiladoras, su estructura y Operación. Primera ed. México. Instituto Mexicano de Contadores Públicos A.C. 194.

ACOSTA MICHEL, L F. Pérez Robles, A. (1996). "Los Precios de Transferencia en México".

CONTADURÍA Pública. Abril. Año 24. D.F. México. Instituto

Mexicano de Contadores Públicos, A.C. 184.

ANDERSON, David R., Dennis j Sweeney y Thomas A. Williams. (2013). Sstatistics for Business and Economics. Ed. West Publishing Company, New York.

BAKER \& MCKENZIE Internacional. (2004). Precios de Transferencia, América Latina. Bettinger, H. (2008). Precios de Transferencia, sus efectos fiscales. Ediciones ISEF, México. BETTINGER Barrios, H. (1999). Precios de Transferencia Sus Efectos Fiscales. 8edición. México. ISEF. 329.

CRUZ Camacho, J. (2001). Precios de Transferencia. Un enfoque empresarial (material de conferencia). Primera ed. Mexico, D.F.Instituto Mexicano de Ejecutivos Internacionales ( IMEFI). CÓDIGO FISCAL de la Federación. (República Mexicana). (2009, Diciembre 31). Disponible en http://www.diputados. gob.mx/inicio.htm [Consultada 2011, Septiembre 26]. Ley Impuesto Sobre la Renta. (República Mexicana). (2009, Diciembre 31). Disponible en http://www.diputados.gob. $\mathrm{mx}$ /inicio.htm [Consultada 2011, Septiembre 26.

LEY FEDERAL de Derechos de los Contribuyentes. (República Mexicana). (2009, Diciembre 31). Disponible en http://www. diputados.gob. mx/inicio.htm [Consultada 2011, Septiembre 26] GÓMEZ Cotero, J.J. (2004). Precios de Transferencia Una Versión Jurídica. Traducido de la $3^{a}$ Ed. México. DOFISCAL EDITORES. 217.

HERNÁNDEZ Santoyo, J.C. Vázquez Sánchez, Ch.B., 2005. 
Precios de Transferencia Aplicación Práctica Total. Primera Ed. México. DOFISCAL EDITORES. 327.

HORNGREN, Ch. Sundem, G. 1994. Contabilidad Administrativa.

Traducido de la Novena ed. Inglés. Novena. México. PrenticeHall Hispanoamericana, S.A. 920.

LUNA Castillo, A., 1996. Metodología de las Tesis. Primera ed. México. Trillas. 127.

NASH John (1996), Ley de los grandes números, Ed Universidad de Prinston, EUA. Premio Nobel de Economía 1996.

RABY, N. (2008). International Transfer Pricing 2008. Price water house Coopers LLP, United Estate

REAL Academia Española. Asociación de Academias de la Lengua Española, 2005. Diccionario panhispánico de dudas. Bogotá Colombia. Talleres Gráficos de Quebecor World Bogotá, S.A. 833.

LA LEY DE IMPUESTO sobre la Renta Mexicana, establecida en la Secretaria de Hacienda y Crédito Público (2009-2014).

OECD. (1995). Transfer Pricing Guidelines for Multinational Enterprises and Tax Administrations. Organisation for Economic Co-operation and Development 2001. France.

Citado de ARTí́culos EN PUblicaCiones PERIÓdicas:

CURIEL García, M. Cabrera Nolasco, A. 2005. Precios de transferencia. Puntos Finos. México. Vol. IV. No.75. 54 - 63.

HURTADO Mendoza, M. Ahrens, E. 2005. Esquema de Precios de Transferencia en México. Puntos Finos. México. Vol. IV No.73. 26-35.

RIZO Rivas, JM. Guerra Correa, B. 2006. Jerarquización de Métodos en Materia de Precios de Transferencia. Puntos Finos. México. Vol. III No. 97. 56-61.

Fecha de Recepción del Artículo: 27 de enero de 2019

FeCHa de ACeptación: 03de marzo de 2019

VERSIÓn FinAL: 24 de abril de 2020 